\title{
A construção do conhecimento, as intervenções metodológicas e os novos saberes e fa- zeres na cultura digital rural
}

Mauren Porciuncula Moreira da Silva

Orientador(a): Profa. Dra. Léa da Cruz Fagundes

data da defesa: 04 de dezembro de 2009

As tecnologias digitais de informação e comunicação estão modificando a nossa cultura, não só a urbana, como também a rural, principalmente com o surgimento da Agroinformática. Este momento histórico vem sendo denominado de Revolução Digital, ocasionando uma ruptura social entre cidadãos incluídos e excluídos digitalmente. Somente cumprindo os pré-requisitos de acesso, educacionais e mobilização, fica caracterizado o processo integral de inclusão digital. Aqui nesta tese o foco é algo que deve ser considerado primordial para a inclusão digital, mas que geralmente passa despercebida pela literatura da chamada Sociedade da Informação: a questão cognitiva. As questões para as quais se buscam respostas nesta tese são: Como incluir digitalmente produtores rurais? Como ocorre a construção do conhecimento de produtores rurais? Que intervenção metodológica aparece efetiva para a construção de suas habilidades e competências digitais? Que novos saberes e fazeres são apresentados durante e após processos de inclusão digital? Embasada em concepções construtivistas sobre os processos de desenvolvimento e de aprendizagem, esta tese apresenta a construção do conhecimento em processos de inclusão digital no meio rural, a partir do desenvolvimento de habilidades e competências digitais durante o desenvolvimento de Projetos de Aprendizagem. Através de uma pesquisa-ação, analisa a construção do conhecimento, as intervenções metodológicas e os novos saberes e fazeres de produtores rurais em processos de inclusão digital, à luz de indicadores extraídos do referencial teórico piagetiano e freireano para tal. Ao analisá-los, qualitativamente e descritivamente, é possível perceber que (i) os sujeitos, ao desenvolverem Projetos de Aprendizagem, aprendem a aprender; (ii) que intervenções metodológicas construtivistas parecem levar a uma metodologia que embasa processos educativos, mas que o mais relevante à prática educativa é a conhecimento de teorias construtivistas interacionistas para intervir; (iii) e que a construção de saberes possibilita o repensar de um novo fazer. Além destes achados educacionais, foi possível concluir que a inclusão digital no meio rural deve-se à ação de empreendedores e, decisivamente, de políticas públicas para a continuidade de acesso às tecnologias digitais de informação e comunicação no meio rural.

Palavras-chave: Inclusão digital rural. Construção do conhecimento. Intervenções metodológicas construtivistas interacionistas. Novos saberes e fazeres rurais.

Referência:

SILVA, Mauren Porciuncula Moreira da. A construção do conhecimento, as intervenções metodológicas e os novos saberes e fazeres na cultura digital rural - Orientadora: Léa da Cruz Fagundes - 2009. Tese (doutorado) - Programa de Pós-Graduação em Informática na Educação, Centro de Estudos Interdisciplinares em Novas Tecnologias da Educação, Universidade Federal do Rio Grande do Sul, 2009, Porto Alegre. 